\title{
Mediation of shock and drug-produced effects on avoidance responding
}

\author{
L. K. MARTIN, BARBARA J. POWELL AND D. K. KAMANO \\ GALESBURG STATE RESEARCH HOSPITAL, ILLINOIS
}

The effects of amobarbital sodium and shock intensity on avoidance learning were studied testing hypotheses regarding factors mediating their known effects. The results did not confirm a previous notion that amobarbital enhanced avoidance responding through a reduction of freezing behavior. On the other hand, freezing behavior and avoidance are related to shock intensity. Unexpectedly, escape latency was greatly slowed by the drug, leading to speculation that perhaps drug effects were mediated by increased punishment for nonresponding.

Moderate dosages of amobarbital sodium have been found to increase the number of conditioned avoidance responses (CARs) emitted during an avoidance acquisition period (Kamano, Martin, \& Powell, 1966; Powell, Martin, \& Kamano, 1965), a result which the authors suggest as reflecting a diminution by the drug of a response tendency (freezing) which is incompatible with active avoidance responding. Specifically, amobarbital was seen as 'breaking up' freezing behavior (immobility accompanied by urination and defecation), thereby enabling the animal to emit an active, instrumental response.

This freezing behavior seems qualitatively quite similar to that generally accepted as the behavioral manifestation of the conditioned emotional response (CER). Using this behavioral definition of the CER, Annau \& Kamin (1961) found that the strength of the CER varles directly with shock intensity. On this basis, it seems likely that the tendency to freeze would similarly increase with shock intensity. Moreover, it follows that if freezing is incompatible with active avoidance, decreases in avoidance responding associated with increases in shock intensity may, as previously speculated, be due to a heightened tendency to emit incompatible freezing responses. Further, if amobarbital does obtund the freezing reaction, the reported increase in CARs (relative to placebos), should be least at low shock intensities, but should increase as shock intensity goes up. In line with this reasoning, the present study will test the following hypotheses: (1) Freezing behavior (as measured through a rating system for general activity Kriekhaus, Miller, \& Zimmerman, 1965) and defecation rate will increase as a function of shock intensity, while CARs will decrease. (2) Ss trained under amobarbital will manifest less freezing and defecation and a greater number of CARs than those trained under placebo. (3) The mean differences in total CARs between drug and placebo groups will increase as a function of shock intensity.

\section{Subjects}

The Ss were 150 male Wistar albino rats which were 75-85 days old at the beginning of the experiment. Insofar as possible, early environmental factors such as handling, litter size, age at weaning, etc.were standard for all Ss.

\section{Apparafus and Procedure}

The open field was built after the description of Denenberg, Carlson, \& Stephens (1962). The avoldance apparatus was a standard Miller-Mowrer jump box. The jump box, $\mathrm{CS}$, and US are described in detail elsewhere (Kamano, Martin, \& Powell, 1966).

Prior to avoidance training, Ss were tested in the open fleld and were assigned randomly to experimental groups on the basis of open field defecation and ambulation scores. Avoidance training consisted of 20 trials per day for five consecutive days. The avoldance situation involved a standard two-way barrier crossing task. Each trial consisted of light(CS) followed 5 sec later by shock (US) with an intertrial interval ranging from 20-40 Bec. Ss were assigned to elther drug ( $30 \mathrm{mg} / \mathrm{kg}$ amobarbital) or placebo groups, and to either a 50, 150, 500, 1000, or $1500 \mu \mathrm{A}$ shock (US) intensity condition. The drug dosage level was selected on the basis of prior results for its optimum enhancement of avoidance responding (Kamano, Martin, \& Powell, 1966; Martin, Powell, \& Kamano, 1966). The experimental design was a 2 by 5 factorial (Winer, 1962) with 15 Ss per cell. In addition to number of CARs, data were also collected on other behaviors, including defecation, general activity level and during CS-US interval (see Kriekhaus, Miller \& Zimmerman, 1965), and escape latencies.

Results

The mean CAR scores for each group are presented in Table 1, along with group mean scores for the other behavioral measures.

The first hypothesis was confirmed by an analysis of the activity ratings and defecation scores in that as shock intensity increased, activity level decreased (F $=3.82, \mathrm{df}=4 / 140, \mathrm{p}<.01$ ), while defecations increased $(F=3.89, d f=4 / 140, p<.01)$. However, the second hypothesis was only partially confirmed in that while Ss trained under amobarbital defecated less ( $F=11.47$, df $=1 / 140, \mathrm{p}<.01)$ and emitted more CARs $(\mathrm{F}=9.06$, df $=1 / 140, p<.01$ ) than placebos, differences in general activity both before and during the CS-US period were nonsignificant.

The third hypothesis, that differences (favoring drug Ss) in number of CARs as a result of amobarbital ad- 
Table 1

Group means for total CAR scores and behavior concomitants

\begin{tabular}{lccccc}
\hline & \multicolumn{5}{c}{ Shock Intensity } \\
& 50 & 150 & 500 & 1000 & 1500 \\
\hline Drug & & & & & \\
$\quad$ CAR & 50 & 35 & 37 & 36 & 24 \\
$\quad$ Defecation & 22 & 35 & 32 & 34 & 33 \\
Activity Before CS & 3.37 & 3.56 & 3.53 & 3.64 & 3.50 \\
Activity During CS & 2.86 & 3.10 & 3.18 & 3.30 & 3.25 \\
Escape Latency & 8.30 & 10.26 & 8.24 & 7.48 & 6.44 \\
Placebo & & & & & \\
CAR & 46 & 39 & 23 & 18 & 19 \\
Defecation & 33 & 38 & 38 & 36 & 39 \\
Activity Before CS & 3.31 & 3.42 & 3.54 & 3.54 & 3.52 \\
Activity During CS & 2.95 & 2.95 & 3.22 & 3.10 & 3.15 \\
Escape Latency & 6.20 & 5.46 & 6.02 & 5.52 & 5.02 \\
\hline
\end{tabular}

ministration would increase as a function of shock intensity, was in the predicted direction $(F=1.45$, df $=4 / 140, p>.10$ ) but was not significant, due to the large amount of error variance.

In addition to results bearing directly on the hypotheses, an interesting result was obtained from data dealing with escape latency. This measure was significant both in terms of drug $(F=78.13, d f=1 / 140, p<.001)$ and shock intensity ( $F=6.57, d f=4 / 140, p<.01)$.

\section{Discussion}

The data confirm previous results with regard to the effects of amobarbital (Kamano, Martin, \& Powell, 1966; Powell, Martin, \& Kamano, 1965) and shock intensity in a two-way shuttlebox avoidance task (e.g., Johnson \& Church, 1965; Levine, 1966; Moyer \& Korn, 1964) on avoidance behavior, in that amobarbital administration was associated with a rise in CARs, while increased shock intensity was associated with a decrease in CARs.

The results confirmed the first hypothesis: Freezing behavior did increase and CARs did decrease as shock intensity increased, a result demonstrating the hypothesized negative relationship between freezing and avoidance responding. This result offers support for the idea that these two behaviors are incompatible and further that response decrements associated with rising shock intensity may result from increased freezing.

Powell, Martin, \& Kamano (1965) have spoken of amobarbital as obtunding freezing; according to this interpretation, amobarbital should produce a general increase in all types of behavior. However, since amobarbital increased the number of CARs emitted, but did not break up freezing behavior, the above interpretation is insufficient to explain the present data. So by contrast, freezing may mediate the effect of shock intensity upon avoidance, but evidently not the effect of amobarbital. Absence of a common mediator may, in part, account for the lack of significance in the interaction between these two factors.

The earliest (temporally) and most reliable effects of both the drug and shock intensity variables on avoidance behavior was a retarding effect upon escape latency. Largely because this effect precedes the emergence of the CAR, it is possible to consider escape time effect as "primary" and to think of other observed differences as proceeding from it. This point of view is derived from theoretical formulations which described learning as a "dropping out" of irrelevant responses. According to this, an animal learns to avoid because all other behaviors are punished and, therefore, drop in probability; i.e., a process of elimination brought about by punishment. In this way the relationship between escape and avoidance becomes causal, not coincidental, and Ss taking longer to escape experience more punishment. This idea seems plausible, and it should be possible to test its adequacy by conducting a study in which escape time ( and hence duration or amount of punishment) is made equal for all Ss. If under such conditions the amobarbital-placebo differences in avoidance disappear, the process of elimination explanation would be valid.

\section{References}

ANNAU, A., \& KAMIN, L. J. The conditioned emotional response as a function of intensity of the US. J. comp. physiol. Psychol., 1961, 54, 242-246.

DENENBERG, V. H., CARLSON, P. V., \& STEPHENS, M. W. Effects of infantile shock upon emotionality at weaning. J. comp. physiol. Psychol., 1962, 55, 819-820.

KAMANO, D. K., MARTIN, L. K., \& POWELL, BARBARA J. Avoidance response acquisition and amobarbital dosage levels. Psychopharmacologia, 1966, 8, 319-323.

KRIEKHAUS, E. E., MILLER, N. E., \& ZIMMERMAN, P. Reduction of freezing behavior and improvement of shock avoidance by d-amphetamine. J. comp. physiol. Psychol, 1965, 60, 36-40.

JOHNSON, J. L., \& CHURCH, R. M. Effects of shock intensity on nondiscriminative avoidance learning of rats in a shuttle-box. Psychon. Sci., 1965, 3, 497-498.

LEVINE, S. UCS intensity and avoidance learning. $J$. exp. Psychol, $1966,71,163-164$.

MOYER, K. E., \& KORN, J. H. Effects of UCS intensity on the acquisition and extinction of an avoidance response. J. exp. Psychol., 1964, 67, 352-359.

POWELL, BARBARA, J., MARTIN, L. K., \& KAMANO, D. K. Effects of amobarbital sodium and meprobamate on acquisition of conditioned avoidance. Psychol Rep., 1965, 17, 691-694. 